\title{
Optimization of Nigerian Satellites in Flood Disaster Preparedness and Response
}

\author{
** Aderoju Olaide .M, Patricia Bassey, ,* Oyewumi Ademuyiwa .S ,** Onuoha Hilda \\ ${ }^{* *}$ Department of Strategic Space Applications, National Space Research \&Development Agency, Abuja. \\ "Department of Geography and Planning, University of Jos.
}

\begin{abstract}
Nigeria as a nation suffers the effects of Climate Change majorly through flood events. Recent flood disasters in Nigeria have been of major concern to people, communities and institutions. In a bid to mitigate the extent of damage and casualties during a flood disaster, this study aimed to promote the use of Nigeria satellites in the preparedness phase of flood disaster management cycle for more practicable and effective response and mitigation. The study also identifies the relevant agencies to collaborate with the National Space Research and Development Agency (NASRDA) in order to promote synergy towards attaining a stable disaster risk management in Nigeria; and provides a framework for improving and managing disaster preparedness and response using Nigerian satellites and through geospatial approach. The approach employed was a combination of satellite imagery, imagery intelligence and geospatial information with the help of Information Communication Technology to plan ahead for any flood event during the pre-disaster phase. The incorporation of geospatial techniques using the Nigerian earth observation and communication satellites in disaster preparedness and response will strengthen our contingency plan provided there is synergy, commitment and information sharing among relevant agencies.
\end{abstract}

Key Words: Flood, Preparedness, Response, Disaster and Satellites.

\section{Introduction}

In the past four decades, economic losses due to natural hazards such as, floods disasters have increased in folds and have also resulted in major loss of human lives and livelihoods, the destruction of economic and social infrastructure, as well as environmental damages during this period. (Munich Re, 2002). In 2006, Abam defined flood as large volume of water which arrives at and occupy the stream channel and its flood plain in a time too short to prevent damage to economic activities including homes. According to the Hyogo framework for Action in 2005, it was stated that the goal was to reduce disaster loss by 2015 through building resilience to disaster in order to reduce the loss of lives, social, economic and environmental assets. Okereke (2007) listed the consequences of urban flooding in his studies in Dhaka, Bangladesh to include: loss of human lives, flooding of houses, streets, inflow to soak away, municipal pollution, damage to properties, health hazards, cleanup costs, disruption of services, traffic problems, adverse effects on aesthetics, disturbances on wildlife habitats, economic loses and infrastructural damage. Recurring floods and other disasters have been identified as a serious threat to sustainable development. Floods cause about one third of all deaths, one third of all injuries and one third of all damage from natural disasters (Askew, 1999). Significantly, flood disasters result from human-created vulnerability which is an outcome of our interacting with the environment by some human activities such as designing and locating our infrastructure, exploiting natural resources, concentrating our population and so on (Hualou, 2011).

Flooding is the most common environmental hazard in Nigeria (Etuonovbe, 2011). Generally, the occurrence of flooding in Nigeria is usually in three main forms: coastal flooding, river flooding and urban flooding (Folorunsho and Awosika 2001; Ologunorisa, 2004). Flooding are common features in Nigeria during Urban flooding occurs in towns, on flat or low-lying terrain especially where little or no provision has been made for surface drainage, or where existing drainage has been blocked with municipal waste, refuses and eroded soil sediments (Folorunsho and Awosika 2001; Ologunorisa, 2004).

Disaster Preparedness focuses on warning and forecasts impending disaster and often entails processes in order to reduce losses. According to Action Aid International (2006) flood hazards are natural phenomena, but damage and losses from floods are the consequence of human action. Flash flooding or urban flooding destroys the produce e.g. crop, rice paddy, fruit tree and vegetables thereby posing the risk of hunger to those engaged in subsistence farming and great loss to those engaged at a commercial scale (Kolawole et al., 2011). With the increasing number of urban dwellers worldwide, the number of people at risk or vulnerable to flood hazards is likely to increase. Any increase in disasters, whether large or small, will threaten development gains and hinder the implementation of the Millennium Development Goals (UN-ISDR, 2008).

Space based information can be use to assist public agencies to prepare for, avert and reduce the consequences of emergencies and improve the response capability of emergency responders. Satellite Remote 
Sensing has the potentiality of acquiring geospatial information about a disaster and disaster prone area spatialtemporarily and in a consistent manner. Spatial information is important in the disaster preparedness phase, especially related to the prediction and forecasting of disasters (e.g. drought, floods), the design of early warning systems and (community based) disaster preparedness programs. The 2012 flood event in Nigeria has been described as the worst in four decades. These events have made most of the country's main rivers to force their ways over their banks which made a large number of both the urban and the rural areas submerged. The 2012 flood event in Nigeria has brought a devastating and unexpected hardship to the affected victims in the some states, hence the use of geospatial technique for mapping and analysis for emergency management and planning is required (Ojigi et al, 2013). With the launch of the NigeriaSat-2, NigeriaSat-X and NigComSat-1R satellites, Nigeria can promote the use of its Space technology and also utilizes her capacity in geospatial analysis in any flood disaster preparedness, response and mitigation by proper planning and coordinated synergy among relevant agencies.

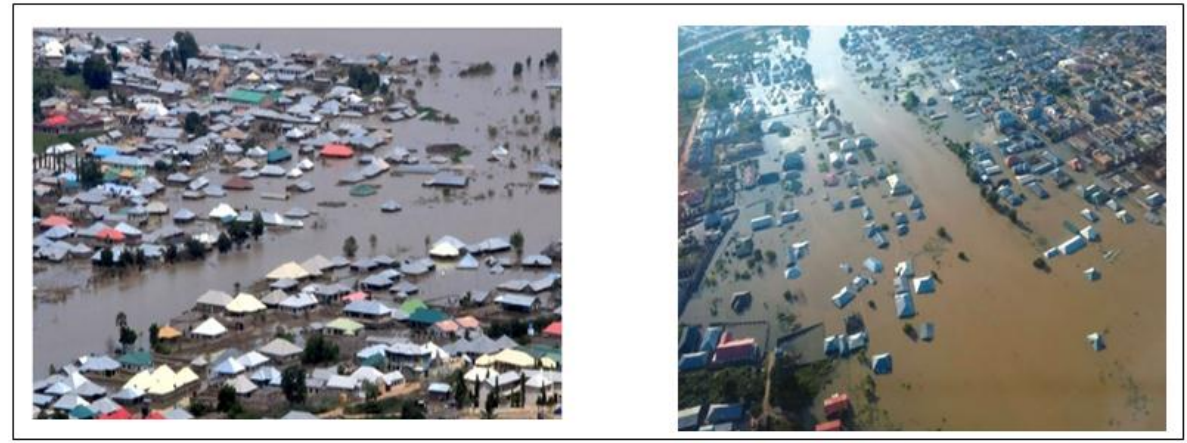

Figure 1.0: 2012 Flood Disaster Images in Nigeria

\section{Aim}

This study is aimed to promote the use of Nigeria satellites in the preparedness phase of flood disaster management cycle for more practicable and effective response and mitigation.

\section{Objectives}

1. Identifies the relevant agencies to collaborate with the National Space Research and Development Agency (NASRDA) in order to promote synergy towards attaining a stable disaster risk management in Nigeria. 2. Provides a framework for improving and managing flood disaster preparedness and response using Nigerian satellites and through geospatial approach.

\section{Nigerian Satellites and Its Applications}

Nigeria as the giant of Africa launched the NigeriaSat-2, NigeriaSat-X (earth Observation satellites) and NigComSat-1R (a communication satellite) in to the space orbit in August and December 2011 respectively. Nigeria Sat-2 was launched in August, 2011. It is high resolution satellite spatial resolutions of $2.5 \mathrm{~m}$ panchromatic and $5 \mathrm{~m}$ multispectral and with area coverage (swath width) 20 by $20 \mathrm{~km}$ with the ability to rapidly produce accurate mapping to updates the existing information and acquiring new mapping information. It is has the Red, Green, Blue and Near -infrared band. The Nigeria Sat-2 allows for environmental and disaster management, infrastructure mapping, settlement classification, development of urban green spaces, service provision maps, and access control mechanisms regional planning, security.

NigeriaSat-X was launched in August, 2011 alongside NigeriaSat-2. It was designed and built by Nigerian Engineers in the UK. It is a medium resolution satellite with a resolution of $22 \mathrm{~m}$ multispectral. It is has the Red, Green and Near -infrared band with a swath width of $600 \mathrm{~km}$. The NigeriaSat-X allows for data for mapping, agricultural monitoring, environmental and disaster management.

NigComSat-1R is a replacement satellite for NigComSat-1 Satellite. It is a critical Information Communication Technology (ICT) backbone infrastructure to drive the National Information Communication Technology (ICT) revolution in providing revenue diversification for the Nation and offering cost effective solution and affordable access to meet Nigeria's telecommunications, broadcast, aviation, maritime, defense and security needs. The satellite has a life-span of 15 years and was designed to meet the needs of telecommunications, maritime, defense, broadcast media in Africa and parts of Europe and Asia. It has 28 active transponders, and band of $\mathrm{Ku}, \mathrm{Ka}, \mathrm{C}-\mathrm{Band}$ and L-Band. The combination of these three satellites (NigeriaSat-2, NigeriaSat-X and NigComSat-1R) would help Nigeria and the rest of the world achieve a great deal in improving and managing disaster preparedness, mitigation and response. 


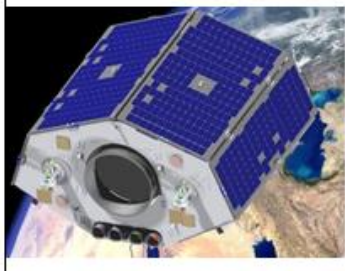

NigeriaSat-2 Satellite

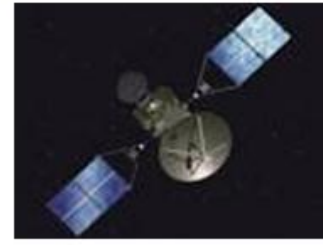

NigcomSat-1R Satellite

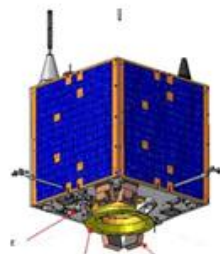

NigeriaSat-X Satellite

Figure 2.0: Images of Nigerian Satellites in Space

\section{Methodology}

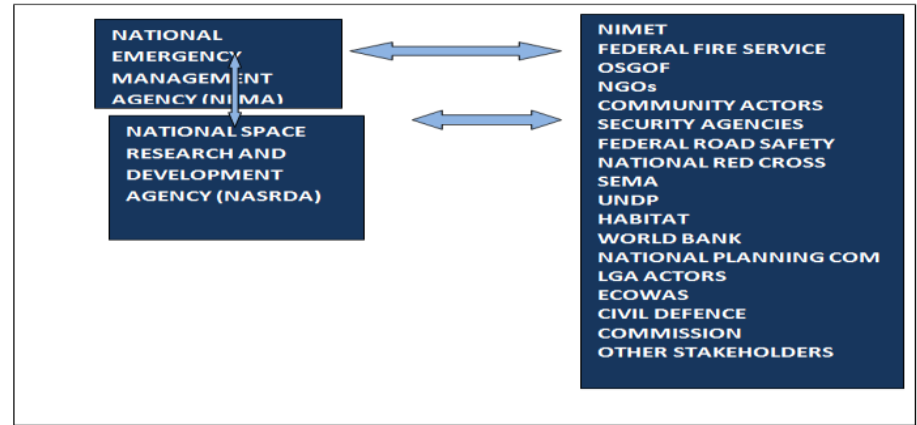

Figure 3.0: Major Actors in Disaster Risk Management

The identified agencies are the major actors in disaster risk management in Nigeria with National Emergency Management Agency (NEMA) as a principal actor of all the agencies. National Space Research and Development Agency (NASRDA) whose satellites (NigeriaSat-2, NigeriaSat-X and NigComSat-1R) were recently launched into the space orbit with of its major goal is monitoring and managing disasters plays a major role in disaster risk management. National Emergency Management Agency (NEMA) and NASRDA have a strong collaboration in areas of disaster management under the platform of UN-SPIDER with NASRDA hosting the UN-SPIDER regional support office in Nigeria. The UN-SPIDER mission statement is to ensure that all international and regional organizations have access to and develop the capacity to use all type of Space-based information to support the full disaster management cycle. Thus it is a challenge that all other actors must come to the party by exploring space-based information to development its capacity disaster management by exploring and utilizing the Nigerian space based asset. The full optimization of the Nigerian satellites in the area of flood disaster preparedness and response will enhance a positive mitigation achievement and speedy resilient provided there is synergy and information sharing among actors. The above workflow is a simple framework on how all the agencies must work together, share information and also very importantly defining each and every actor's role in attaining sustainability in flood disaster preparedness and response. disaster.

This is a simple framework that can be used during the preparedness and response phase of any

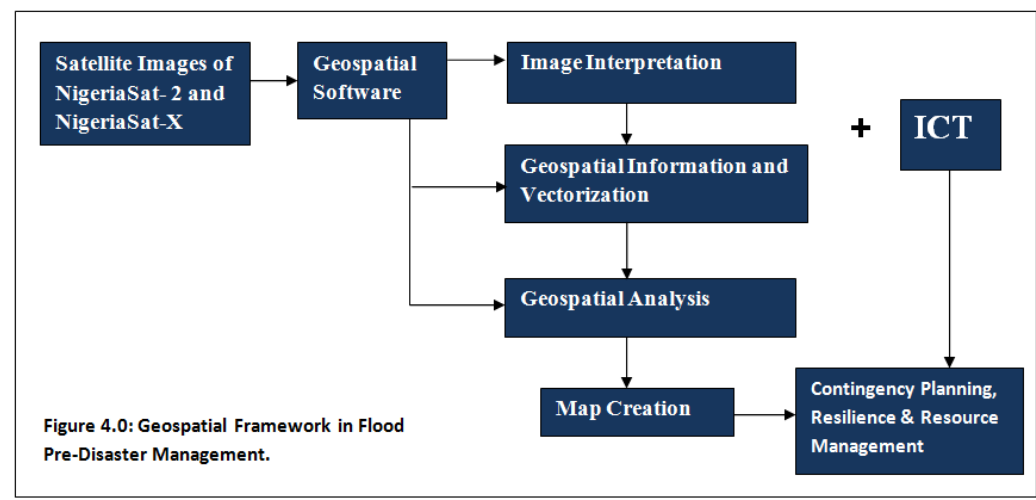


This framework simply describes how imageries of the NigeriaSat-2, NigeriaSat-X and NigComSat-1R can be used in the mitigation of flood risk disaster. In this model, Imageries from the Nigeria satellites are processed using geospatial software and expert in the field of satellite remote sensing and Geographic Information Systems (GIS) interprets the information observed from the satellite imagery as geospatial information. This geospatial information is extracted through a process of Vectorization using geospatial software and furthermore geospatial analysis is done to enhance spatial modeling, simulations for disaster mitigation, monitoring and prediction for any sustainable development. The use of NigComSat-1R through Information Communication and Telecommunication (ICT) helps in the area of information dissemination through broadcast, internet networks and video conferencing during early warnings, awareness creation programs and also in the areas of Tele-medicine when there are critical medical cases.

\section{Space Technology in Flood Disasters Preparedness and Response}

Remote sensing and GIS technology can be especially useful and desirable when applied during the planning and decision making that involves both natural and man-made disaster occurrence.

\section{Flood Disaster Preparedness}

Identification and planning in the preparedness phase of flood disaster management cycle is usually done long before the occurrence of a disaster. In this particular phase, humans, facilities, infrastructures and other assets in the community which are vulnerable to natural and man-made disaster in possible identified disaster prone areas by Satellites (NigeriaSat-2 and NigeriaSat-X). After the identification of these assets for proper inventory, the planning ways to get these assets and humans protected follows. With the advent of space technology, remote sensing and Geographic information system (GIS) can help in the hazard zoning of the community which depends on the vulnerability assessment and human settlements. Space technology can also help in assets identification and mapping of these assets for proper planning in order to combat possible occurrence of any disaster. The preparedness phase is mainly tasks to be done to prepare for an imminent disaster and this is done long before the occurrence of a disaster. In the case, the identification of hazard prone areas is identified by remote sensing satellite and the imageries are for proper mapping of the whole area showing infrastructures, hazard prone areas, hydrology and relief, and other geospatial information present. The Nigeria communication satellite NigComSat-1R plays a vital role in flood preparedness disaster in the areas of early warnings, awareness creation program through media broadcast, mobile phones communication, and internet services. The vulnerability assessment and Risk maps can be done with the help of Geographic information systems (GIS) because of its statistical and analytical capabilities.

The pre-disaster planning is usually done with the help of information dissemination during early warnings and media broadcast, maps and scenarios can be analyzed and response measures can be designed and planned. Evacuation routes can be planned and displayed for use by emergency managers since Geographic information systems (GIS) is a supportive tool in decision making, and planning

\section{Response}

This is in the post disaster phase of the disaster management cycle which happens during and after the occurrence of a disaster. During this phase, the evacuation route is the map of the affected community is used to evacuate people from their homes. This is the effort to minimize the hazard caused by disaster and it involves the following:

a) Evacuation: During the course of any disaster, the people living in affected areas are evacuated and they are relocated to a hazard free area. This can be done by the use of existing maps, land use maps, terrain and relief maps aerial photographs of the affected area.

b) Emergency Relief: In this case the rescue team should provide immediate assistance to save lives, improve health and support morale of the affected populate. Through this, the affected people are relocated to a safe place where temporary camps are provided for shelter. This will deal with meeting the basic needs of the people until when permanent and sustainable solution can be found. They provide medical facilities, water, food, aid blankets and clothes. The NigComSat-1R also provides facilities for the use of video conferencing in providing medical aid that requires special attention like surgery through the telemedicine program. The telemedicine program has been flagged up by the National Space research and Development Agency (NASRDA) in conjunction with some major specialist hospitals in Nigeria to provide immediate and special medical aid to severe medical situation during a disaster. The telemedicine program encompasses multidiscipline like medical practitioners, computer scientist, system engineers and many among others.

c) Damage Assessment: Remote sensed data and GIS they provide vital information on the affected community by a disaster. Here satellites provide comprehensive synoptic and multi-spectral coverage of large area in real time. Identify the affected areas, map extent of damage with the help of GIS and the map before the 
occurrence of any disaster, and it can be used to determine the extent of damage, destroyed facilities, affected lives hence helping in determining the costs for easy planning after a disaster.

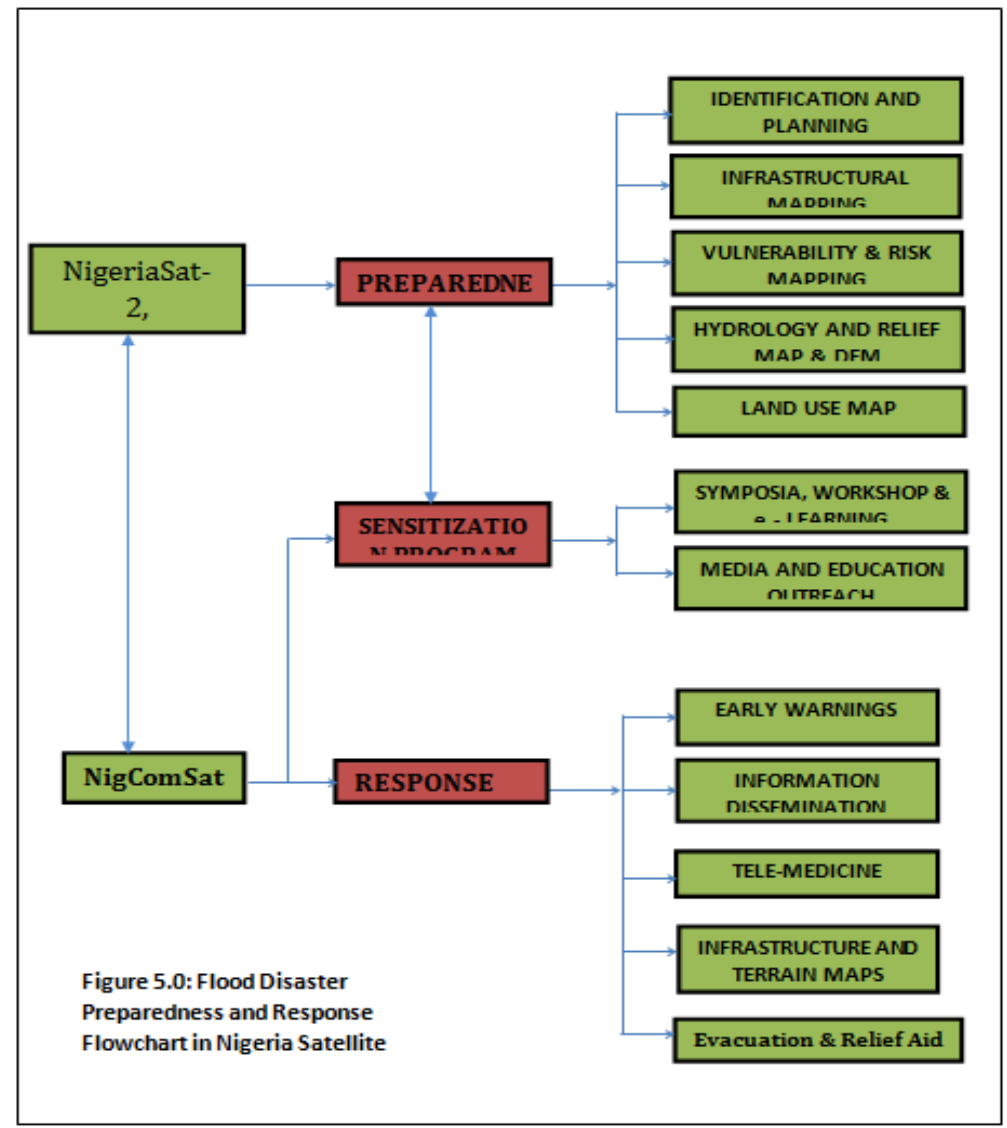

\section{Conclusion}

Successful optimization of the Nigerian Satellites (NigeriaSat-2, NigeriaSat-X and NigComSat-1R) in flood disaster preparedness and response, and also synergy among the stakeholders can accelerate a country's resilience to flood disaster and also help transform its people's socioeconomic prospects. The conceptual framework towards flood disaster mitigation the preparedness and response phase of the disaster management cycle using the Nigerian satellites will lead greater efficiency in retrieving information and speedier access to information for emergency situations, the ability to build scenarios and explore a wider range of "what-if" alternatives for decision support system for prediction and monitoring flood disaster risk management. This will lead towards to achieving the goal of proper contingency planning, reduce the excessive budget towards emergency relief and aids and also provide an opportunity to improve living standards in the country which could reduce the loss of life and property during the course of flood disaster.

\section{Recommendation}

National actors must work together in a coordinated manner for the benefit of Nigeria. Roles of all actors (agencies) must be defined and information sharing is key to attain substantial results. Concurrent capacity building in geospatial technology must be encouraged and also using imageries from the Nigerian satellites for a major disaster risk preparedness and emergency response. Awareness creation at the grassroots level on the capability of space technology in disaster monitoring and forecasting by both the local government and communities actors to also appreciate and make them identify their own role as a contributor towards attaining a disaster resilience environment. 


\section{References}

[1]. Abam, T.S.K., 2006. Development Policy Framework for Erosion and Flood Control in Nigeria. EARTHWATCH - Magazine for Environment and Development Experts in Nigeria, 5(1), 25-32.

[2]. ActionAid (2006). Climate Change, Urban Flooding and the Rights of the Urban Poor in Africa: Key Findings from Six African Cities, A Report by ActionAid October 2006.

[3]. Askew, A.J. (1999). Water in the International Decade for Natural Disaster Reduction. In: Leavesley et al (Eds) Destructive Water: Water-caused Natural Disaster, their Abatement and Control. IAHS Publication No. 239.

[4]. Etuonovbe, A.K., 2011. Devastating Effect of Flooding in Nigeria. FIG Working Week 2011

[5]. Folorunsho, R. and Awosika, L.F., 2001. Flood Mitigation in Lagos, Nigeria through Wise Management of Solid Waste: a case of Ikoyi and Victoria Islands; Nigerian, Paper presented at the UNESCO-CSI workshop, Maputo 19-23 November 2001.

[6]. Hualou, L (2011). Disaster Prevention and Management: A Geographical Perspective. Disaster Advances 4(1) January 2011.

[7]. Hyogo Framework for Action,2005 - 2015, Building the Resilience of Nations and Communities to Disaster. Report of the World Conference on Disaster Reduction, 18 - 22 January 2005, Kobe, Hyogo, Japan. www.unisdr.org/wcdr. (Assessed last on the $15^{\text {th }}$ August, 2013)

[8]. Kolawole, O.M, Olayemi, A.B. and Ajayi, K.T. (2011). Managing Flood in Nigerian Cities: Risk Analysis and Adaptation Options - Ilorin City as a Case Study. Archives of Applied Science Research 3(1):17-24.

[9]. Munich Re Topics (2002): Natural catastrophes in 2002. Review of the Year: 2002

[10]. Ojigi M.L, Abdulkadir, F.I, Aderoju, M.O. (2013): Geospatial Mapping and Analysis of the 2012 flooding Disaster in central parts of Nigeria; $8^{\text {th }}$ GIS symposium, Dammaram, Saudi Arabia.

[11]. Okereke R. A., 2007. Incidence of Flooding in Southern Nigeria, International Journal of Environmental Issues 5(1 \& 2).

[12]. Ologunorisa, E.T., 2004. An Assessment of Flood Vulnerability Zones in the Niger Delta, Nigeria. International Journal of Environmental Studies, U.K., 61(1).

[13]. UN-International Strategy for Disaster Reduction (UN-ISDR) (2008) "Disaster Risk Reduction Strategies and Risk Management Practices: Critical Elements for Adaptation to Climate Change" Submission to the UNFCCC Adhoc. Working Group on Long Term Cooperative Action. Available at: www.unisdr.org/.../risk reduction/climatechange/.../IASC ISDR_paper_cc_and_DDR.pdf (Accessed 24 ${ }^{\text {th }}$ July. 2013) 